\section{What is Design?}

An Interview with Charles Eames

The following statement by Charles is an expression of his approach to the design process. These words (...) and his answers to the questions are an explanation of the Eames philosophy and background material for this record of the work of the Eames Office. Were asked by Madame Amic and answered by Charles. The questions and answers were the conceptual basis of the exhibition What is Design? An edited and slightly changed version of the questions was used as the basis of the 1972 film Design $Q$ of $A$.

What is your definition of "design?"

A plan for arranging elements in such a way as to best accomplish a particular purpose.

Is design an expression of art (an art form)? The design is an expression of the purpose. It may (if it is good enough) later be judged as art.

Is design a craft for industrial purposes? No- but design may be a solution to some industrial problems.

What are the boundaries of design?

What are the boundaries of problems?

Is design a discipline that concerns itself with only one part of the environment? No.

It is a method of general expression? No- it is a method of action.

Is design a creation of an individual? No- because to be realistic one must always admit the influence of those who have gone before. ...or a creation of a group?

Often.

Is there a design ethic?

There are always design constraints and these usually include an ethic.

Does design imply the idea of products that are necessarily useful?

Yes- even though the use might be surely subtle.

It is able to cooperate in the creation of works reserved solely for pleasure?

Who would say that pleasure is not useful?

Ought form to derive from the analysis of function?

The great risk here is that the analysis may not be complete.

Can the computer substitute for the designer?

Probably, in some special cases, but usually the computer is an aid to the designer.

Does design imply industrial manufacture? Some designs do and some do not-depending on the nature of the design and the requirements.

Is design an element of industrial policy? A. Certainly; as in any other aspect of quality, obvious or subtle, of the product. It seems that anything can be an element in policy.

Ought design to care about lowering costs? A product often becomes more useful if the costs are lowered without harming the quality.

Does the cration of design admit constraint? Design depends largely on constraints.

What constraints?

The sum of all constraints. Here is one of the few effective keys to the design problem-the ability of the designer to recognize as many of the constraint as possible-his willingness and enthusiasm for working within these constraints-the constraints of price, of size, of strength, balance, of surface, of time, etc.; each problem has its own peculiar list.

Does design obey laws? Aren't constrints enough?
Ought the final product to bear the trademark of the designer? Of the research office?

In some cases, one may seem appropriate. In some cases, the other, and certainly in some cases both.

What is the relation of design to the world of fashion (current trends)?

The objects of fashion have usually been designed with the particular constraints of fashion in mind.

\section{Is design ephemeral?}

Some needs are ephemeral. Most designs are ephemeral.

Ought it to tend towards the ephemeral or towards permanence?

Those needs and designs that have a more universal quality will tend toward permanence.

To whom does design address itself: to the greatest number (the masses)? to the specialists or the enlightened amateur? To a privileged social class?

To the need.

Can public action aid the advancement of design?

The proper public action can advance most anything,

After having answered all these questions, do you feel yau have been able to practice the profession of "design" under satisfactory conditions, or even optimum conditions? Yes.

Have you been forced to accept compromises? I have never been forced to accept compromises but y have willingly accepted constraints.

What do you feel is the primary condition for the practice of design and its propagation? Recognition of the need.

What is the future of design?

(No answer)

(1907-1978) Northamerican architect. He designed from toys to building in association with his wife, Ray Kaiser. 